\title{
Observed risk of recurrent bleeding and thromboembolic disease in COVID-19 patients with gastrointestinal bleeding
}

\section{다 $(9)$}

\author{
Authors \\ Emmanuel Attah ${ }^{1}$, Tracey A. Martin², Emily S. Smith ${ }^{1}$, Sunena Tewani ${ }^{3}$, Kaveh Hajifathalian², Reem Z. Sharaiha², Carl \\ V. Crawford ${ }^{2}$, David Wan ${ }^{2}$
}

Institutions

1 Medicine, Weill Cornell Internal Medical College, New York Presbyterian Hospital, New York, New York, United States

2 Division of Gastroenterology and Hepatology, Weill Cornell Medical College, New York Presbyterian Hospital, New York, New York, United States

3 Division of Hospital Medicine, Weill Cornell Medical College, New York Presbyterian Hospital, New York, New York, United States

submitted 18.12 .2020

accepted after revision 14.4 .2021

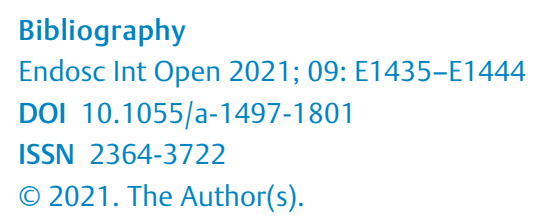

This is an open access article published by Thieme under the terms of the Creative Commons Attribution-NonDerivative-NonCommercial License, permitting copying and reproduction so long as the original work is given appropriate credit. Contents may not be used for commercial purposes, or adapted, remixed, transformed or built upon. (https://creativecommons.org/licenses/by-nc-nd/4.0/)

Georg Thieme Verlag KG, Rüdigerstraße 14,

70469 Stuttgart, Germany

Corresponding author

Emmanuel Attah, MD, Medicine, Weill Cornell Medical

College, 525 East 68th Street, New York New York 10065,

United States

Fax: +1-212-7468051

eoa9003@nyp.org

\section{ABSTRACT}

Background and study aim COVID-19 patients are at increased risk for venous thromboembolism (VTE) requiring the use of anticoagulation. Gastrointestinal bleeding (GIB) is increasingly being reported, complicating the decision to initiate or resume anticoagulation as providers balance the risk of thrombotic disease with the risk of bleeding. Our study aimed to assess rebleeding rates in COVID-19 patients with GIB and determine whether endoscopy reduces these rebleeding events. We also report 30-day VTE and mortality rates.

Methods This was a retrospective study evaluating 56 COVID-19 patients with GIB for the following outcomes: 30-day rebleeding rate, 30-day VTE rate, effects of endoscopic intervention on the rate of rebleeding, and 30-day mortality.

Results The overall rates of VTE and rebleeding events were $27 \%$ and $41 \%$, respectively. Rebleeding rates in patients managed conservatively was $42 \%$ compared with $40 \%$ in the endoscopy group. Overall, $87 \%$ of those who underwent invasive intervention resumed anticoagulation vs. $55 \%$ of those managed medically $(P=0.02)$. The allcause 30 -day mortality and GIB-related deaths were $32 \%$ and $9 \%$, respectively. Mortality rates between the endoscopic and conservative management groups were not statistically different ( $25 \%$ vs. $39 \%$; $P=0.30)$.

Conclusions Although rebleeding rates were similar between the endoscopic and conservative management groups, patients who underwent intervention were more likely to restart anticoagulation. While endoscopy appeared to limit the duration that anticoagulation was withheld, larger studies are needed to further characterize its direct effect on mortality outcomes in these complex patients.

\section{Introduction}

Coronavirus disease 2019 (COVID-19) is a multiorgan system disease, with approximately $17 \%-19 \%$ of patients experiencing gastrointestinal (GI) side-effects [1-3]. Specifically, 2\%-13\% of patients infected have GI bleeding (GIB) [1]. This increased incidence of GIB in hospitalized COVID-19 patients has been at- tributed to the management strategies of infection-related hypercoagulability, particularly the use of anticoagulation [4].

Anticoagulation is a longstanding risk factor for GIB in the general population [5]. The incidence of GIB in hospitalized patients on therapeutic anticoagulation is 115/10 000 personyears with $2 \%-12 \%$ annual incidence [6-8]. Current literature shows that hospitalized COVID-19 patients have an increased 
incidence of venous thromboembolism (VTE) ranging from 11\% to $42 \%$ [9-12]. Recent studies have also shown a mortality benefit with anticoagulation therapy in these patients $[13,14]$. Our hospital's protocol recommends anticoagulation in those with a high clinical suspicion for deep vein thrombosis (DVT) or pulmonary embolism. Whether this increased use of anticoagulation has led to an increased incidence of GIB has yet to be determined.

GIB management requires adequate resuscitation, proton pump inhibitor (PPI) therapy, and endoscopy within 24 hours for acute upper GIB (UGIB) [15]. For suspected lower GIB (LGIB), recommendations support the next available colonoscopy after adequate bowel preparation [16]. At this time, there is limited evidence on the benefits of endoscopic interventions in the described COVID-19 population. While several studies have reported cessation of bleeding with conservative management alone, there is no evidence to support either invasive or conservative treatment and its impact on 30-day outcomes [4, 17-19]. Of note, our previous study characterized the most common etiologies of GIB among patients with COVID-19. In this study, it was suggested that conservative management was a reasonable approach to initial management of GIB in COVID-19 patients as there was no difference in transfusion requirements between patients who underwent endoscopy compared with those who were managed conservatively [4]. However, this study did not assess the effects of invasive management and anticoagulation on the 30-day outcomes (rate of rebleeding, VTE, and mortality) of these COVID-19 patients with GIB.

The aim of the current study was to characterize the 30-day rate of rebleeding and thrombotic events in hospitalized COVID-19 patients with GIB. Our secondary aims were to determine the effects of endoscopic intervention on the rate of rebleeding and to assess 30-day mortality outcomes.

\section{Methods}

This was a retrospective, multicenter, cohort study that reviewed all 56 patients with a positive result on reverse transcription polymerase chain reaction (RT-PCR) nasopharyngeal swabs and GIB who were admitted to an academic tertiary care center and a nonteaching hospital at the height of the pandemic in New York City between 4 March and 25 May 2020. All patients included were aged over 18 years. GIB was defined as hematemesis, coffee ground emesis (CGE), melena, hematochezia or maroon stools, and evidence of a $2 \mathrm{~g} / \mathrm{dL}$ decline in hemoglobin (Hgb) from peak to nadir values, or heart rate $>100$ bpm or systolic blood pressure $<100 \mathrm{mmHg}$. Patients were clinically classified as UGIB vs. LGIB if positive for melena, CGE, or hematemesis vs. hematochezia or maroon stools, respectively. VTE was defined as the development of a DVT, pulmonary embolism, or embolic stroke confirmed by imaging studies (venous ultrasound/Doppler, computed tomography [CT] pulmonary embolus study, CT head, magnetic resonance imaging of the brain). Rebleeding was defined as a bleeding event after 72 hours of cessation of the index bleed [20,21]. Anticoagulation therapy in this study refers to the use of one of the following anticoagulant agents: heparin, enoxaparin, or apixaban. None of the patients were on coumadin, or a direct oral anticoagulant other than apixaban, prior to their bleed. Antiplatelet therapy in this study refers to the use of aspirin, clopidogrel, or the combination of the two. None of the patients were on any other antiplatelet agents prior to their bleed. The study was approved by the institutional review board on 4 June 2020.

A total of 56 patients with a positive COVID-19 RT-PCR test and GIB were admitted during the study period. GIB patients were identified through GI consultation order placed for GIB in the electronic medical record. Additionally, the Gl consultation service page logs and endoscopy database (ProVation) were used to further cross reference and capture all possible cases during the study period. Once identified and confirmed as having COVID-19 symptoms and COVID-19 PCR-positive with GIB, the bleed was then characterized according to its clinical presentation, anatomical location, and etiology. Endoscopic findings and therapeutic outcomes were described for both UGIB and LGIB. The data extraction also included information on age, sex, medical comorbidities, medications, clinical features, laboratory findings, imaging, complications, and outcomes of each patient. The primary outcomes were the rates of rebleeding and thromboembolic events within 30 days from the initial bleed. The secondary outcomes were the impact of endoscopy on rebleeding rates and 30-day mortality outcomes.

\section{Statistical analysis}

Descriptive statistical analysis was reported as counts, proportions, rates, and means with standard deviations (SDs). Variables were compared using chi-squared and Fisher's exact tests. All analyses were based on non-missing data, and missing data were not imputed. All tests were two-tailed with a significance level of alpha $=0.05$. All analyses were performed with IBM SPSS Statistics for Macintosh, Version 25.0. (IBM Corp, Armonk, New York, USA).

\section{Results}

\section{Demographics}

A total of 56 inpatients with RT-PCR-positive COVID-19 and GIB were evaluated (38 males and 18 females; mean age 69 [SD 14] years [1 SD]) ( Table 1). Prior history was significant for coronary artery disease and/or cerebrovascular events $(n=18)$, cancer $(n=14)$, atrial fibrillation ( $n=8)$, DVT and/or pulmonary embolism $(n=9)$, and GIB $(n=9)$.

Of the 56 patients, 41 (73\%) were on anticoagulation prior to diagnosis of GIB (18 on enoxaparin, 19 on heparin, and 4 on apixaban), including 25/35 UGIB patients (71\%) and 16/21 LGIB patients (76\%). Prior to the bleeding event, 25/56 patients (45 $\%$ ) were on antiplatelet therapy (22 on aspirin, 2 on aspirin/clopidogrel, and 1 on clopidogrel), and 19/56 patients (34\%) were on a PPI.

The mean systolic blood pressure at time of the bleed was 123 (SD 25.4) $\mathrm{mmHg}$ (average 1 SD) and the mean heart rate 99 (SD 22.4) bpm. The mean difference in $\mathrm{Hgb}$ from peak to nadir was 3.9 (SD 2.0) g/dL. Mean Hgb at the time of the bleed 
- Table 1 Demographics.

\begin{tabular}{|c|c|c|c|}
\hline Characteristic & $\begin{array}{l}\text { Total } \\
(n=56)\end{array}$ & $\begin{array}{l}\text { UGIB } \\
(n=35)\end{array}$ & $\begin{array}{l}\text { LGIB } \\
(n=21)\end{array}$ \\
\hline Age, mean (SD), years & $69(14)$ & $71(15)$ & $66(10)$ \\
\hline \multicolumn{4}{|l|}{ Sex, n (\%) } \\
\hline - Male & $38(68)$ & $23(66)$ & $15(71)$ \\
\hline - Female & $18(32)$ & $12(34)$ & $6(29)$ \\
\hline BMI, mean (SD), kg/m² & $28(6)$ & $26(10)$ & $30(9)$ \\
\hline \multicolumn{4}{|l|}{ Prior history, n (\%) } \\
\hline - Diabetes mellitus & $27(48)$ & $20(57)$ & $7(33)$ \\
\hline - Coronary artery disease & $18(32)$ & $13(37)$ & $5(24)$ \\
\hline - Cancer & $14(25)$ & $11(31)$ & $3(14)$ \\
\hline - Chronic kidney disease & $8(14)$ & $5(14)$ & $3(14)$ \\
\hline - Atrial fibrillation & $8(14)$ & $7(20)$ & $1(5)$ \\
\hline $\begin{array}{l}\text { - DVT and/or pulmonary } \\
\text { embolism }\end{array}$ & $9(16)$ & $5(14)$ & $4(19)$ \\
\hline - GIB prior to admission & $9(16)$ & $5(14)$ & $4(19)$ \\
\hline \multicolumn{4}{|l|}{ Medication, n (\%) } \\
\hline - NSAIDs & $19(34)$ & $11(31)$ & $8(38)$ \\
\hline - Statin therapy & $26(46)$ & $16(46)$ & $10(48)$ \\
\hline - Chronic steroids & $4(7)$ & $3(9)$ & $1(5)$ \\
\hline $\begin{array}{l}\text { - Anticoagulation prior to } \\
\text { diagnosis }\end{array}$ & $41(73)$ & $25(71)$ & $16(76)$ \\
\hline - Antiplatelet & $25(45)$ & $16(46)$ & $9(43)$ \\
\hline - PPI & $19(34)$ & $12(34)$ & $7(33)$ \\
\hline
\end{tabular}

UGIB, upper gastrointestinal bleed; LGIB, lower gastrointestinal bleed; SD, standard deviation; BMI, body mass index; DVT, deep vein thrombosis; GIB, gastrointestinal bleed; NSAID, nonsteroidal anti-inflammatory drug; PPI, proton pump inhibitor.

was 8.5 (SD 2.3) g/dL, and the mean Hgb nadir was 7.2 (SD 1.7) $\mathrm{g} / \mathrm{dL}$. The mean blood urea nitrogen and creatinine levels on presentation were 58 (SD 38.8) $\mathrm{mg} / \mathrm{dL}$ and $2.44(2.42) \mathrm{mg} / \mathrm{dL}$, respectively.

\section{Bleeding events}

Out of 35 patients with UGIB, 26 (74\%) presented with melena, 3 (9\%) with hematemesis, 2 (6\%) with CGE, 1 (3\%) with bright red blood per rectum (BRBPR), 1 (3\%) with positive nasogastric tube gastric occult blood, and $2(6 \%)$ with BRBPR and melena. In all, 13/35 UGIB patients (37\%) had rectal tubes in place. Of the 21 LGIB patients, 19 (90\%) presented with BRBPR and 2 (10\%) with melena; $13 / 21$ LGIB patients (62\%) had a rectal tube in place.

\section{Interventions}

New York Presbyterian Hospital was at the epicenter during the peak of the pandemic, and luminal evaluation was performed in patients admitted with melena, BRBPR, or hematemesis noted
- Table 2 Etiology of gastrointestinal bleed.

\begin{tabular}{|c|c|c|c|}
\hline Characteristic, n (\%) & $\begin{array}{l}\text { Total } \\
(n=56)\end{array}$ & $\begin{array}{l}\text { UGIB } \\
(n=35)\end{array}$ & $\begin{array}{l}\text { LGIB } \\
(n=21)\end{array}$ \\
\hline Gastric/duodenal ulcer & $8(14)$ & $7(20)$ & $1(5)^{1}$ \\
\hline Esophagitis & $1(2)$ & $1(3)$ & $0(0)$ \\
\hline Diverticulosis & $3(5)$ & $0(0)$ & $3(14)$ \\
\hline Ischemic colitis & $2(4)$ & $0(0)$ & $2(10)$ \\
\hline Angioectasia & $1(2)$ & $0(0)$ & $1(5)$ \\
\hline Rectal ulcer & $6(11)$ & $0(0)$ & $6(29)$ \\
\hline Ulcer and esophagitis & $2(4)$ & $2(6)$ & $0(0)$ \\
\hline Ulcer and malignant nodule & $1(2)$ & $1(3)$ & $0(0)$ \\
\hline Rectal ulcer and diverticulosis & $2(4)$ & $0(0)$ & $2(10)$ \\
\hline Rectal ulcer and mass/polyp & $1(2)$ & $0(0)$ & $1(5)$ \\
\hline Unknown source of bleeding & $29(52)$ & $24(69)$ & $5(24)$ \\
\hline \multicolumn{4}{|c|}{$\begin{array}{l}\text { UGIB, upper gastrointestinal bleed; LGIB, lower gastrointestinal bleed. } \\
{ }^{1} \text { Presented with LGIB (bright red blood per rectum); however, the patient } \\
\text { had an upper endoscopy at a later time, which revealed a clean-based gas- } \\
\text { tric ulcer with no stigmata of bleed. }\end{array}$} \\
\hline
\end{tabular}

on examination with ongoing hemodynamic instability or severe anemia unresponsive to transfusions of packed red blood cells (PRBCs). The decision of whether to proceed with endoscopy was made after multidisciplinary team discussions with key input from the primary team and the gastroenterology team. Endoscopy would then be carried out after approval from the chief of endoscopy.

At the time of bleeding, 38/41 patients (93\%) had their anticoagulation therapy discontinued. All 35 patients characterized as UGIB were started on a PPI and 12 of them (34\%) underwent endoscopy. The most common etiology of UGIB was gastric and duodenal ulcers (7/35 [20\%]) ( Table 2). Five of the 35 UGIB cases (14\%) underwent therapeutic interventions with clips, injection, cautery or a combination of these methods ( $\triangleright$ Table 3 ). One patient underwent both surgical and interventional radiology procedures with coil embolization and a wedge gastrectomy for a gastric ulceration that was positive for primary adenocarcinoma.

Eight of the 21 patients with LGIB (38\%) underwent endoscopy. The most common etiology of LGIB was rectal ulceration (6/21 [29\%]), followed by diverticular bleeding (3/21 [14\%]) ( Table 2). One patient required a total colectomy for ischemic colitis, and interventional radiology successfully managed two other patients with fluoroscopy-guided coil embolization for an active diverticular bleed. Of the 21 LGIB patients, 1 (5\%) underwent cautery for an angioectasia, and 2(10\%) required rectal packing for rectal ulcerations. Within 24 hours of both noninvasive management or endoscopy, all patients had documented cessation of hemorrhage. The mean number of PRBC units transfused in this cohort during hospitalization was 2.6. There was no statistical difference in the number of PRBCs transfused (3.45 vs. 2.14; $P=0.1$ ) or the Charlson Comorbidity Index $(\mathrm{CCl}$; 


\begin{tabular}{|l|c|c|c|}
\hline Table 3 Interventions. & \multicolumn{3}{|l}{} \\
\hline Characteristic, $\mathbf{n}$ (\%) & $\begin{array}{l}\text { Total } \\
(\mathbf{n = 5 6}\end{array}$ & $\begin{array}{l}\text { UGIB } \\
\mathbf{( n = 3 5 )}\end{array}$ & $\begin{array}{l}\text { LGIB } \\
\mathbf{( n = 2 1 )}\end{array}$ \\
\hline Consult team & $50(89)$ & $30(86)$ & $20(95)$ \\
\hline Medical & $53(95)$ & $35(100)$ & $18(86)$ \\
\hline Noninvasive medical only & $33(59)$ & $23(66)$ & $10(48)$ \\
\hline Endoscopic evaluation & $20(36)$ & $12(34)$ & $8(38)$ \\
\hline - Therapeutic intervention & $8(14)$ & $5(14)$ & $3(14)$ \\
\hline - Clip & $2(4)$ & $2(6)$ & $0(0)$ \\
\hline - Cautery & $1(2)$ & $0(0)$ & $1(5)$ \\
\hline - Rectal packing & $2(4)$ & $0(0)$ & $2(10)$ \\
\hline - Clip/injection/cautery & $2(4)$ & $2(6)$ & $0(0)$ \\
\hline - Injection/clip & $1(2)$ & $1(3)$ & $0(0)$ \\
\hline - No therapeutic intervention & $12(21)$ & $7(20)$ & $5(24)$ \\
\hline Surgical intervention & $3(5)$ & $2(6)$ & $1(5)$ \\
\hline Interventional radiology & $4(7)$ & $2(6)$ & $2(10)$ \\
\hline $\begin{array}{l}\text { Both surgical and interventional } \\
\text { radiology }\end{array}$ & $1(2)$ & $1(3)$ & $0(0)$ \\
\hline $\begin{array}{l}\text { Endoscopic, interventional radi- } \\
\text { ology, surgical }\end{array}$ & $1(2)$ & $1(3)$ & $0(0)$ \\
\hline UGIB, upper gastrointestinal bleed; LGIB, lower gastrointestinal bleed. \\
\hline
\end{tabular}

4.0 vs. 4.7 , respectively; $P=0.37$ ) between those who underwent endoscopy and those who did not.

\section{Rebleeding}

A total of $23 / 56$ patients $(41 \%)$ had a clinically significant rebleeding event. The rebleeding rate was common in both the groups of patients managed conservatively and those undergoing endoscopy ( $42 \%$ and $40 \%$, respectively) ( $\vee$ Fig. 1 ). Of the 35 UGIB patients, 14 (40\%) had a documented rebleeding event.

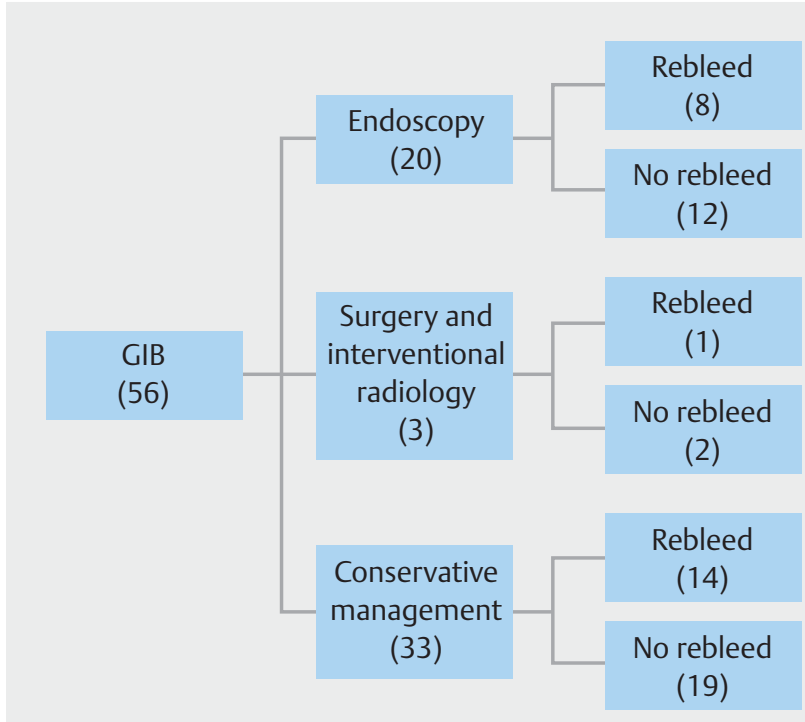

GIB: gastrointestinal bleed

Fig. 1 Rebleeding according to management approach. GIB, gastrointestinal bleed.

Anticoagulation was withheld for all 14 patients at the time of rebleeding. In UGIB patients, the rebleeding rate was $50 \%$ in those who underwent endoscopy and $35 \%$ in those who were managed conservatively ( $\triangleright$ Table 4$)$.

Nine of the 21 LGIB patients (43\%) had a documented rebleeding event. Two of these patients (22\%) had a lower endoscopic procedure upon evaluation of the initial bleed. There was no difference in rebleeding rate when comparing LGIB patients who underwent lower endoscopy with those managed conservatively ( $25 \%$ vs. $60 \% ; P=0.14$ ).

Overall, there was no difference in rebleeding rate among patients who were restarted on anticoagulation after the initial bleed compared with those who did not restart anticoagulation after the initial bleed ( $42 \%$ vs. $40 \% ; P=0.89$ ) ( Fig. 2 ).

- Table 4 30-day outcomes (venous thromboembolism and rebleeding).

\begin{tabular}{|c|c|c|c|}
\hline Characteristics, n/N (\%) & Total & UGIB & LGIB \\
\hline Total VTE & $15 / 56(27)$ & $5 / 35(14)$ & $10 / 21(48)$ \\
\hline - VTE before initial GIB & $7 / 56(13)$ & $3 / 35(9)$ & $4 / 21(19)$ \\
\hline - VTE after initial GIB & $8 / 56(14)$ & $2 / 35(6)$ & $6 / 21(29)$ \\
\hline Total rebleeding events & $23 / 56(41)$ & $14 / 35(40)$ & $9 / 21(43)$ \\
\hline Rebleeding after conservative management & $14 / 33(42)$ & $8 / 23(35)$ & $6 / 10(60)$ \\
\hline Rebleeding after endoscopic evaluation & $8 / 20(40)$ & $6 / 12(50)$ & $2 / 8(25)$ \\
\hline $\begin{array}{l}\text { Rebleeding with restarting anticoagulation after GIB } \\
\text { Rebleeding without restarting anticoagulation after GIB } \\
P \text { value }\end{array}$ & $\begin{array}{l}15 / 36(42) \\
8 / 20(40) \\
0.89\end{array}$ & $\begin{array}{l}8 / 21(38) \\
6 / 14(43)\end{array}$ & $\begin{array}{l}7 / 15(47) \\
2 / 6(33)\end{array}$ \\
\hline
\end{tabular}




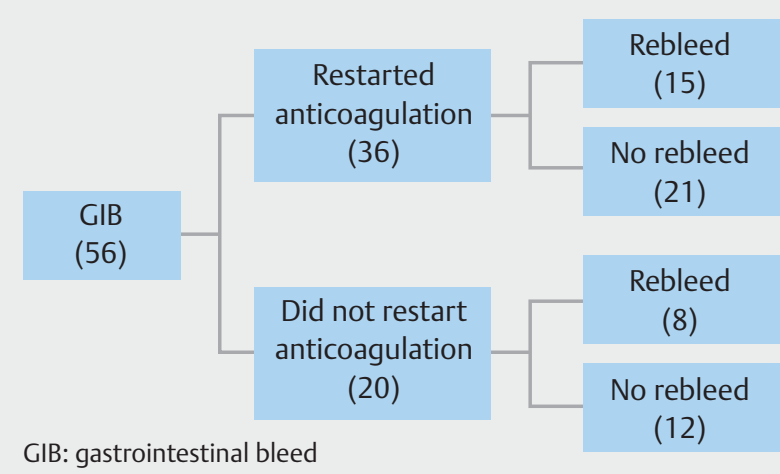

- Fig. 2 Rebleeding according to anticoagulation management. GIB, gastrointestinal bleed.

\section{Thrombotic events and anticoagulation}

A total of 41 patients were on anticoagulation therapy prior to their GIB. Of these patients, 30 received anticoagulation for prevention of thrombosis associated with COVID-19 infection, 6 were treated for pre-existing conditions (such as atrial fibrillation and history of clots prior to hospitalization), and 5 were receiving anticoagulation for VTE diagnosed in the hospital ( 1 for embolic stroke, 3 for DVTs, and 1 for pulmonary embolism); 18 patients were on enoxaparin, 19 were on heparin, and 4 were on apixaban. Of these 41 patients, 38 (93\%) had their anticoagulation discontinued upon their bleeding event.

A total of $15 / 56$ patients (27\%) had a VTE during their hospitalization (7 DVTs, 4 pulmonary embolisms, 1 DVT and pulmonary embolism, 3 embolic cerebrovascular accidents); 8 of these patients ( $53 \%$ ) had VTEs diagnosed with clots after their anticoagulation was discontinued. Anticoagulation was withheld for 4-10 days with a mean of 6 days prior to the diagnosis of VTE in this group.

A total of $20 / 23$ patients ( $87 \%$ ) who underwent invasive intervention/evaluation (i.e. endoscopic evaluation, interventional radiology, and/or surgical intervention) resumed their anticoagulation during hospitalization, whereas only 18/33 pa- tients (55\%) who did not undergo any invasive intervention were able to restart anticoagulation. Patients who underwent invasive intervention were statistically more likely to have anticoagulation initiated or restarted during hospitalization $(87 \%$ vs. $55 \% ; P=0.02$ ). There was no statistical difference in the $\mathrm{CCl}$ between patients who were restarted on anticoagulation after GIB and those who were not restarted on anticoagulation after the bleeding event (4.1 vs. $4.9 ; P=0.31$ ).

\section{0-day mortality}

The all-cause 30-day mortality rate in this cohort was $32 \%$ (18/ 56). The 30-day mortality rate was $40 \%(14 / 35)$ in patients with UGIB and $19 \%(4 / 21)$ in those with LGIB ( $\$$ Table 5). Patients who underwent endoscopic evaluation had a 30-day all-cause mortality rate of $25 \%$ (5/20) compared with $39 \%$ (13/33) in those managed conservatively $(P=0.30)$. The 30 -day bleedingrelated mortality rate was $9 \%(5 / 56)$. Overall, there was no statistically significant difference in 30-day mortality rate between patients who were restarted on anticoagulation and those who were not ( $28 \%$ vs $40 \%$; $P=0.36)$. In addition, there was no difference in mortality rate among patients who were restarted on anticoagulation after endoscopy compared with those who were restarted on anticoagulation after medical management alone (29\% vs. $29 \%$; $P>0.99)$.

The group of patients who died within 30 days comprised $61.1 \%$ males compared with $71.1 \%$ males in the group that survived. There was no difference in age (70.9 vs. 66.7 years; $P=$ 0.29 ) or mean $\mathrm{CCl}$ (4.9 vs. $4.1 ; P=0.31$ ) between those who died compared with those who survived. Overall, $56 \%$ of the group who died were restarted on anticoagulation compared with $74 \%$ in the group who survived $(P=0.18)$. Furthermore, $5 /$ $18(28 \%)$ in the group who died underwent luminal evaluation compared with $15 / 38$ (39\%) in those who survived. Finally, of the 18 patients who died, 14 had UGIBs and 4 had LGIBs ( $>$ Table 6, Fig.3); among the patients who survived, 21/38 had UGIBs and $17 / 38$ had LGIBs.

- Table 5 30-day outcomes (mortality).

\begin{tabular}{|l|r|c|c|}
\hline Characteristics, $\mathbf{n} / \mathbf{N}(\%)$ & Total & UGIB & LGIB \\
\hline Total mortality & $18 / 56(32)$ & $14 / 35(40)$ & $4 / 21(19)$ \\
\hline - Bleed-related mortality & $5 / 56(9)$ & $4 / 35(11)$ & $1 / 21(5)$ \\
\hline - Conservative management mortality & $13 / 33(39)$ & 0.3 \\
\hline - Endoscopic management mortality & $5 / 20(25)$ & \\
\hline Mortality in patients restarted on anticoagulation after initial GIB & $10 / 36(28)$ & 0.36 \\
\hline Mortality in patients not restarted on anticoagulation after initial GIB & $8 / 20(40)$ & \\
\hline Mortality in patients restarted on anticoagulation after endoscopy & $5 / 17(29)$ & \\
\hline Mortality in patients restarted on anticoagulation after medical management alone & $5 / 17(29)$ & $>0.99$ \\
\hline UGIB, upper gastrointestinal bleed; LGIB, lower gastrointestinal bleed; GIB, gastrointestinal bleed. & \\
\hline
\end{tabular}


Dable 6 Characteristics of the patients who died.

\begin{tabular}{|c|c|c|c|c|c|c|c|c|c|}
\hline $\begin{array}{l}\text { Pa- } \\
\text { tient } \\
\#\end{array}$ & $\begin{array}{l}\text { Age, } \\
\text { years }\end{array}$ & Sex & $\begin{array}{l}\text { Type } \\
\text { of } \\
\text { bleed }\end{array}$ & $\begin{array}{l}\text { Endos- } \\
\text { copy }\end{array}$ & Endoscopy findings & Comorbidities & $\mathrm{CCl}$ & $\begin{array}{l}\text { Antico- } \\
\text { agula- } \\
\text { tion }\end{array}$ & $\begin{array}{l}\text { Cause of death } \\
\text { and contributing } \\
\text { factors }\end{array}$ \\
\hline 1 & 89 & $\mathrm{~F}$ & UGIB & No & $\mathrm{N} / \mathrm{A}$ & $\begin{array}{l}\text { HTN, DM, rheumatic } \\
\text { disease, CHF, paroxys- } \\
\text { mal atrial fibrillation }\end{array}$ & 6 & No & $\begin{array}{l}\text { GIB (declined } \\
\text { endoscopy, pallia- } \\
\text { tive management), } \\
\text { COVID-19 }\end{array}$ \\
\hline 2 & 99 & $\mathrm{~F}$ & UGIB & No & $\mathrm{N} / \mathrm{A}$ & HTN, CVA history & 6 & Heparin & $\begin{array}{l}\text { Acute respiratory } \\
\text { failure secondary to } \\
\text { COVID-19 }\end{array}$ \\
\hline 3 & 79 & $\mathrm{~F}$ & UGIB & No & N/A & $\begin{array}{l}\text { HTN, DM, CVA history, } \\
\text { dementia }\end{array}$ & 6 & $\begin{array}{l}\text { Enoxa- } \\
\text { parin }\end{array}$ & $\begin{array}{l}\text { Acute respiratory } \\
\text { failure secondary to } \\
\text { COVID-19 }\end{array}$ \\
\hline 4 & 78 & $\mathrm{~F}$ & UGIB & No & $\mathrm{N} / \mathrm{A}$ & $\begin{array}{l}\text { HTN, DM, CVA, de- } \\
\text { mentia, asthma, cor- } \\
\text { onary artery disease, } \\
\text { lymphoma, history of } \\
\text { peptic ulcer disease }\end{array}$ & 11 & No & $\begin{array}{l}\text { Multiorgan failure; } \\
\text { GIB contributing }\end{array}$ \\
\hline 5 & 64 & M & UGIB & EGD & $\begin{array}{l}\text { Clean-based duode- } \\
\text { nal ulcer }\end{array}$ & CKD, HTN, DM, DVT & 4 & $\begin{array}{l}\text { Enoxa- } \\
\text { parin }\end{array}$ & $\begin{array}{l}\text { Multiorgan failure } \\
\text { secondary to COV- } \\
\text { ID-19, }\end{array}$ \\
\hline 6 & 83 & M & UGIB & EGD & $\begin{array}{l}\text { Oozing duodenal ul- } \\
\text { cer with visible ves- } \\
\text { sel; injected with } \\
\text { epinephrine and } \\
\text { clipped }\end{array}$ & $\begin{array}{l}\text { Atrial fibrillation, HTN, } \\
\text { peptic ulcer disease, } \\
\text { DM, ESRD, CVA }\end{array}$ & 9 & $\begin{array}{l}\text { Enoxa- } \\
\text { parin }\end{array}$ & $\begin{array}{l}\text { Respiratory failure } \\
2 / 2 \text { COVID-19 }\end{array}$ \\
\hline 7 & 50 & M & UGIB & No & $\mathrm{N} / \mathrm{A}$ & $\begin{array}{l}\text { Metastatic colorectal } \\
\text { cancer, CKD, Crohn's } \\
\text { disease }\end{array}$ & 7 & No & $\begin{array}{l}\text { Multiorgan failure } \\
\text { secondary to COV- } \\
\text { ID-19, GIB contri- } \\
\text { buting }\end{array}$ \\
\hline 8 & 79 & M & UGIB & No & $N / A$ & DM, HTN, HLD & 5 & $\begin{array}{l}\text { Enoxa- } \\
\text { parin }\end{array}$ & $\begin{array}{l}\text { Acute respiratory } \\
\text { failure secondary to } \\
\text { COVID-19 }\end{array}$ \\
\hline 9 & 70 & M & UGIB & No & $\mathrm{N} / \mathrm{A}$ & No significant history & 3 & $\begin{array}{l}\text { Enoxa- } \\
\text { parin }\end{array}$ & $\begin{array}{l}\text { Multiorgan failure } \\
\text { secondary to COV- } \\
\text { ID-19 }\end{array}$ \\
\hline 10 & 56 & $\mathrm{~F}$ & UGIB & No & $\mathrm{N} / \mathrm{A}$ & $\begin{array}{l}\text { HTN, DM, sickle cell } \\
\text { trait }\end{array}$ & 2 & Heparin & $\begin{array}{l}\text { ARDS and cardio- } \\
\text { genic shock sec- } \\
\text { ondary to COVID- } \\
19\end{array}$ \\
\hline 11 & 87 & $\mathrm{~F}$ & UGIB & No & $\mathrm{N} / \mathrm{A}$ & DM & 5 & $\begin{array}{l}\text { Pres- } \\
\text { ented } \\
\text { with } \\
\text { GIB; no } \\
\text { antico- } \\
\text { agula- } \\
\text { tion } \\
\text { started }\end{array}$ & $\begin{array}{l}\text { COVID-19 pneu- } \\
\text { monia, pulmonary } \\
\text { embolus (was start- } \\
\text { ed on enoxaparin } \\
\text { despite GIB), GIB } \\
\text { contributing }\end{array}$ \\
\hline 12 & 78 & M & UGIB & No & $\mathrm{N} / \mathrm{A}$ & $\begin{array}{l}\text { Obesity, HTN, DM, } \\
\text { CKD }\end{array}$ & 3 & $\begin{array}{l}\text { Enoxa- } \\
\text { parin }\end{array}$ & $\begin{array}{l}\text { Septic shock, COV- } \\
\text { ID-19 pneumonia }\end{array}$ \\
\hline 13 & 52 & M & UGIB & EGD & $\begin{array}{l}\text { Bleeding gastric ul- } \\
\text { cerations; } 3 \text { hemo- } \\
\text { static clips placed }\end{array}$ & $\begin{array}{l}\text { HTN, DM, coronary } \\
\text { artery disease }\end{array}$ & 2 & Heparin & $\begin{array}{l}\text { ARDS secondary to } \\
\text { COVID-19 (termin- } \\
\text { ally extubated) }\end{array}$ \\
\hline 14 & 79 & M & UGIB & No & $\mathrm{N} / \mathrm{A}$ & $\begin{array}{l}\text { Metastatic prostatic } \\
\text { cancer, pulmonary } \\
\text { embolus }\end{array}$ & 10 & Heparin & $\begin{array}{l}\text { Multiorgan failure } \\
\text { secondary to COV- } \\
\text { ID-19 }\end{array}$ \\
\hline
\end{tabular}




\begin{tabular}{|c|c|c|c|c|c|c|c|c|c|}
\hline \multicolumn{3}{|c|}{ Table 6} & \multirow[b]{2}{*}{$\begin{array}{l}\text { Type } \\
\text { of } \\
\text { bleed }\end{array}$} & \multirow[b]{2}{*}{$\begin{array}{l}\text { Endos- } \\
\text { copy }\end{array}$} & \multirow[b]{2}{*}{ Endoscopy findings } & \multirow[b]{2}{*}{ Comorbidities } & \multirow[b]{2}{*}{$\mathrm{CCl}$} & \multirow[b]{2}{*}{$\begin{array}{l}\text { Antico- } \\
\text { agula- } \\
\text { tion }\end{array}$} & \multirow[b]{2}{*}{$\begin{array}{l}\text { Cause of death } \\
\text { and contributing } \\
\text { factors }\end{array}$} \\
\hline $\begin{array}{l}\text { Pa- } \\
\text { tient } \\
\#\end{array}$ & $\begin{array}{l}\text { Age, } \\
\text { years }\end{array}$ & Sex & & & & & & & \\
\hline 15 & 55 & $\mathrm{M}$ & LGIB & No & $\mathrm{N} / \mathrm{A}$ & $\begin{array}{l}\text { HTN, DM, human im- } \\
\text { munodeficiency virus, } \\
\text { obesity }\end{array}$ & 2 & Heparin & $\begin{array}{l}\text { ARDS secondary to } \\
\text { COVID-19, GIB con- } \\
\text { tributing }\end{array}$ \\
\hline 16 & 53 & $\mathrm{~F}$ & LGIB & $\begin{array}{l}\text { Sigmoi- } \\
\text { dosco- } \\
\text { py }\end{array}$ & Colitis & HTN, hyperthyroidism & 1 & No & $\begin{array}{l}\text { Multisystem organ } \\
\text { failure secondary to } \\
\text { COVID-19 }\end{array}$ \\
\hline 17 & 61 & $\mathrm{M}$ & LGIB & No & $N / A$ & $\begin{array}{l}\text { Cirrhosis, hemochro- } \\
\text { matosis, atrial fibrilla- } \\
\text { tion }\end{array}$ & 4 & Heparin & $\begin{array}{l}\text { Septic shock, COV- } \\
\text { ID-19 pneumonia }\end{array}$ \\
\hline 18 & 64 & M & LGIB & $\begin{array}{l}\text { Colo- } \\
\text { nosco- } \\
\text { py }\end{array}$ & Diverticulosis & Obesity, asthma, DVT & 2 & $\begin{array}{l}\text { Enoxa- } \\
\text { parin }\end{array}$ & $\begin{array}{l}\text { Multiorgan system } \\
\text { failure secondary to } \\
\text { COVID-19 }\end{array}$ \\
\hline
\end{tabular}

CCI, Charlson Comorbidity Index; F, female; M, male; UGIB, upper gastrointestinal bleed; LGIB, lower gastrointestinal bleed; N/A, not applicable; EGD, esophagogastroduodenoscopy; HTN, hypertension; DM, diabetes mellitus; CHF, congestive heart failure; CVA, cerebrovascular accident; CKD, chronic kidney disease; DVT, deep vein thrombosis; ESRD, end-stage renal disease; HLD, hyperlipidemia; GIB, gastrointestinal bleed; ARDS, acute respiratory distress syndrome.

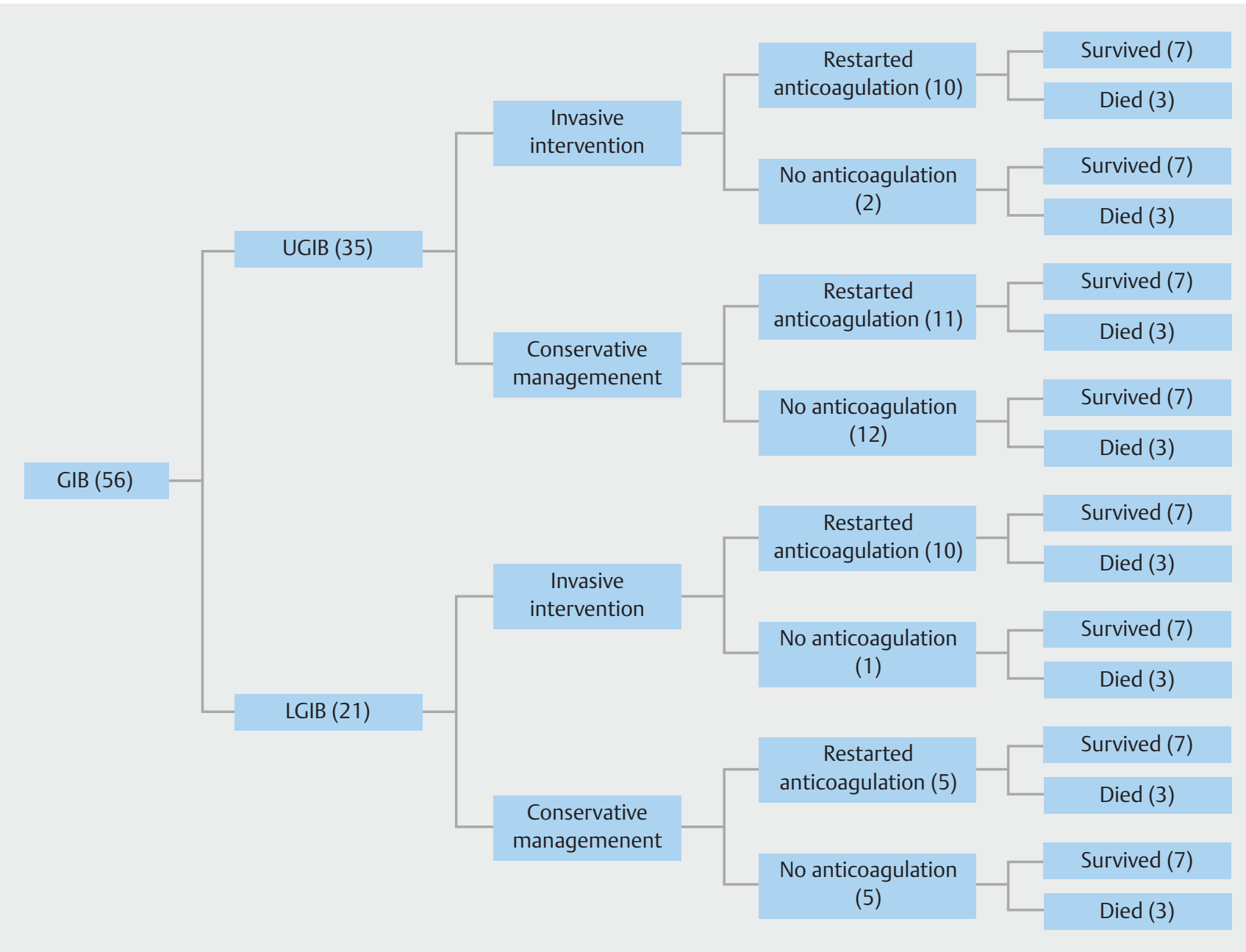

Fig. 3 Outcomes flow chart. GIB, gastrointestinal bleed; UGIB, upper gastrointestinal bleed; LGIB, lower gastrointestinal bleed. 


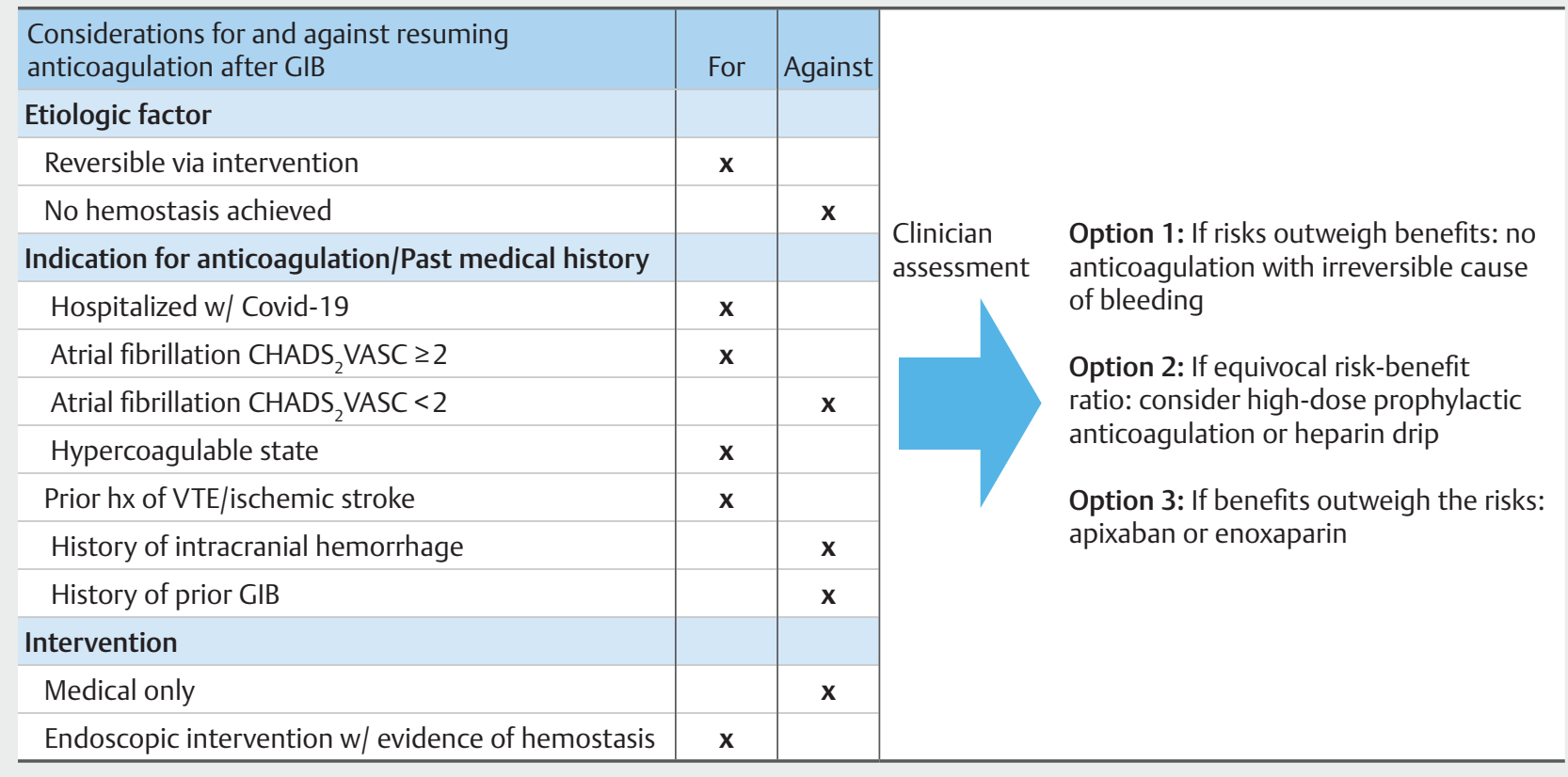

Fig. 4 Restarting anticoagulation considerations. VTE, venous thromboembolism; GIB, gastrointestinal bleed. CHADS 2 VASC is a scoring system for the assessment of stroke risk in patients with atrial fibrillation based on risk factors such as congestive heart failure, hypertension, diabetes mellitus, age $\geq 75$ years, prior history of cerebrovascular events, female sex, age 65-75 years.

\section{Discussion}

In this cohort of COVID-19 patients, there were 56 patients with GIB, 35 of whom had UGIB and 21 had LGIB. Overall, $36 \%$ of patients underwent endoscopic evaluation, with the most common findings being peptic ulcers for UGIB and rectal ulcerations for LGIB. Clinically significant rebleeding events within 30 days of the initial bleed occurred in $41 \%$. There was no difference in rebleeding rate between patients who were restarted on anticoagulation compared with those who were not ( $42 \%$ vs. $40 \%$; $P=0.89$ ). The rate of thromboembolism in this cohort was $27 \%$. The 30 -day all-cause mortality was $32 \%$; however, only $9 \%$ of the cohort died with bleeding being listed as a contributing factor. The UGIB and LGIB mortality rates were $40 \%$ and $19 \%$, respectively. There was no difference in transfusion requirements in patients who underwent endoscopy compared with those who were managed conservatively (3.45 vs. 2.14). Although the rebleeding rates with endoscopic therapy and medical management were similar ( $40 \%$ vs. $42 \%$ ), physicians were statistically more likely to resume anticoagulation when an invasive intervention was performed ( $87 \%$ vs. $55 \%$; $P$ $=0.02$ ).

COVID-19 patients have been shown to have an increased risk of VTE $[7,11,12]$. Several studies have also shown a mortality benefit with anticoagulation usage in this cohort $[13,14]$. As a result, physicians caring for COVID-19 patients with GIB are now faced with the dilemma of whether or not to use anticoagulation agents. In our cohort, $93 \%$ of patients had their anticoagulation withheld due to the bleeding event; $27 \%$ experienced a VTE during their hospitalization, $53 \%$ of whom were diag- nosed after anticoagulation was withheld, thus supporting the importance of reducing the duration of time that anticoagulation therapy is paused in these prothrombotic patients. Thrombotic events including strokes, DVTs, and pulmonary embolisms can be catastrophic, with major repercussions, such as death or permanent neurological deficits. Of our patients with VTE during their hospitalization, seven had DVTs, four had pulmonary embolisms, one had both a DVT and a pulmonary embolism, and three had cerebrovascular accidents. When the decision to withhold anticoagulation arises, the risk and benefits must be weighed carefully, particularly as the incidence of rebleeding in this cohort was as high as $41 \%$. While endoscopic evaluation did not reduce the rebleeding rate in this cohort, it did increase the likelihood that anticoagulation would be restarted. Given that there was no difference in mortality rates between patients who were restarted on anticoagulation after endoscopy compared with those restarted on therapy after conservative management, it seems reasonable to re-challenge COVID-19 patients who stopped bleeding with anticoagulation even if endoscopy could not be performed.

Finally, our data suggest that in patients with similar CCl values, the endoscopic intervention group had a relatively lower 30 -day mortality rate compared with those who were managed conservatively ( $25 \%$ vs. $39 \% ; P=0.30$ ); however, this did not reach statistical significance. As data suggest a potential mortality benefit with anticoagulation in COVID-19 patients, it is plausible that this trend in mortality is related to a higher rate of anticoagulation resumption in the endoscopy group compared with those managed medically $[13,14]$. An alternative explanation is that despite similarity in $\mathrm{CCl}$, it is possible that 
acute decompensated patients at higher mortality risks were less likely to be selected for endoscopy, accounting for the slightly higher mortality rate in the medically managed cohort. Ultimately, larger and more controlled studies are needed to assess whether endoscopic evaluation truly affords a mortality benefit in this population.

When interpreting these results there are limitations that should be considered. In the general population, rebleeding risk often depends on the etiology of the GIB and whether endoscopic hemostasis was achieved, with studies showing a clear reduction in rebleeding risk with endoscopic management for UGIBs [22]. However, in our cohort, endoscopic therapy did not reduce rebleeding rates for UGIB and our lack of randomization, small sample size, and limited number of patients undergoing endoscopic therapy restricts our ability to make generalizable conclusions in COVID-19 patients. Thus, larger studies are needed to further evaluate the effects of endoscopic hemostasis on rebleeding rates. In addition, there is variability in the reporting of GIB, and with only $36 \%$ of patients undergoing endoscopic evaluation during the COVID-19 era, there is a risk of misclassification of bleeding etiology. Furthermore, the decision to opt for endoscopy was not standardized but was based on the patient's respiratory status, degree of hemodynamic stability, provider safety, and resource utilization including personal protective equipment, ventilators, and intensive care unit beds.

Nevertheless, based on our findings we believe that, if deemed safe, it is important to perform endoscopic evaluation as this may limit the duration that anticoagulation is withheld and potentially impact mortality outcomes. As a result of our experience, we have provided a list of factors to consider when weighing risks and benefits of resuming anticoagulation with the aim of guiding providers in their management of anticoagulation in these complex patients ( $\triangleright$ Fig. 4) [23-25].

\section{Conclusion}

GIB in COVID-19 patients has posed a unique challenge for gastroenterologists and healthcare providers as the risk of bleeding vs. VTE events are continuously assessed. Our studies suggest that rebleeding risk in COVID-19 patients remains high regardless of whether they are managed conservatively or with endoscopy. Despite this, endoscopic evaluation appears to increase the likelihood that anticoagulation may be resumed, which ultimately may afford some mortality benefit in these prothrombotic patients. However, larger controlled studies are needed to guide management as we continue to care for these complex patients, balancing the risk of thrombotic disease with the risk of gastrointestinal hemorrhage.

\section{Competing interests}

The authors declare that they have no conflict of interest.

\section{References}

[1] Lin L, Jiang X, Zhang Z et al. Gastrointestinal symptoms of 95 cases with SARS-CoV-2 infection. Gut 2020; 69: 997-1001

[2] Cheung KS, Hung IFN, Chan PPY et al. Gastrointestinal manifestations of SARS-CoV-2 infection and virus load in fecal samples from a Hong Kong cohort: systematic review and meta-analysis. Gastroenterology 2020; 159: 81-95

[3] Mao R, Qiu Y, He JS et al. Manifestations and prognosis of gastrointestinal and liver involvement in patients with COVID-19: a systematic review and meta-analysis. Lancet Gastroenterol Hepatol 2020; 5: 667-678 erratum in Lancet Gastroenterol Hepatol 2020; 5: e6

[4] Martin TA, Wan DW, Hajifathalian K et al. Gastrointestinal bleeding in patients with coronavirus disease 2019: a matched case-control study. Am J Gastroenterol 2020; 115: 1609-1616

[5] Hippisley-Cox J, Coupland C. Predicting risk of upper gastrointestinal bleed and intracranial bleed with anticoagulants: cohort study to derive and validate the QBleed scores. BMJ 2014; 349: g4606

[6] Ray WA, Chung CP, Murray KT et al. Association of oral anticoagulants and proton pump inhibitor cotherapy with hospitalization for upper gastrointestinal tract bleeding. JAMA 2018; 320: 2221-2230

[7] Chen WC, Chen YH, Hsu PI et al. Gastrointestinal hemorrhage in warfarin anticoagulated patients: incidence, risk factor, management, and outcome. Biomed Res Int 2014; 2014: 463767

[8] Landefeld CS, Beyth R]. Anticoagulant-related bleeding: clinical epidemiology, prediction, and prevention. Am J Med 1993; 95: 315-328

[9] Connors JM, Levy JH. COVID-19 and its implications for thrombosis and anticoagulation. Blood 2020; 135: 2033-2040

[10] Bilaloglu S, Aphinyanaphongs Y, Jones S et al. Thrombosis in hospitalized patients with COVID-19 in a New York City health system. JAMA 2020; 324: 799-801

[11] Trigonis RA, Holt DB, Yuan R et al. Incidence of venous thromboembolism in critically ill coronavirus disease 2019 patients receiving prophylactic anticoagulation. Crit Care Med 2020; 48: e805-e808

[12] Middeldorp S, Coppens M, van Haaps TF et al. Incidence of venous thromboembolism in hospitalized patients with COVID-19. J Thromb Haemost 2020; 18: 1995-2002

[13] Billett HH, Reyes-Gil M, Szymanski ] et al. Anticoagulation in COVID19: effect of enoxaparin, heparin, and apixaban on mortality. Thromb Haemost 2020; 120: 1691-1699

[14] Rico-Mesa JS, Rosas D, Ahmadian-Tehrani A et al. The role of anticoagulation in COVID-19-induced hypercoagulability. Curr Cardiol Rep 2020; 22: 53

[15] Lau JYW, Yu Y, Tang RSY et al. Timing of endoscopy for acute upper gastrointestinal bleeding. N Engl J Med 2020; 382: 1299-1308

[16] Strate LL, Gralnek IM. ACG clinical guideline: management of patients with acute lower gastrointestinal bleeding. Am J Gastroenterol 2016; 111: 459-474

[17] Shalimar D, Vaishnav M, Elhence A et al. Outcome of conservative therapy in COVID-19 patients presenting with gastrointestinal bleeding. J Clin Exp Hepatol 2020; 11: 327-333

[18] Richardson S, Hirsch JS, Narasimhan M et al. Presenting characteristics, comorbidities, and outcomes among 5700 patients hospitalized with COVID-19 in the New York City area. JAMA 2020; 323: 2052

[19] Horby P, Lim WS. RECOVERY Collaborative Group. et al. Dexamethasone in hospitalized patients with Covid-19 - preliminary report. N Engl J Med 2021; 384: 693-704

[20] Maggio D, Barkun AN, Martel M et al. Predictors of early rebleeding after endoscopic therapy in patients with nonvariceal upper gastrointestinal bleeding secondary to high-risk lesions. Can J Gastroenterol 2013; 27: 454-458 
[21] Barkun A, Sabbah S, Enns R et al. The Canadian Registry on Nonvariceal Upper Gastrointestinal Bleeding and Endoscopy (RUGBE): endoscopic hemostasis and proton pump inhibition are associated with improved outcomes in a real-life setting. Am J Gastroenterol 2004; 99: 1238-1246

[22] Kahi CJ, Jensen DM, Sung JJY et al. Endoscopic therapy versus medical therapy for bleeding peptic ulcer with adherent clot: a meta-analysis. Gastroenterology 2005; 129: 855-862
[23] Witt DM. What to do after the bleed: resuming anticoagulation after major bleeding. Hematology 2016; 2016: 620-624

[24] Goldstein JN, Greenberg SM. Should anticoagulation be resumed after intracerebral hemorrhage? Cleve Clin J Med 2010; 77: 791-799

[25] Qureshi W, Mittal C, Patsias I et al. Restarting anticoagulation and outcomes after major gastrointestinal bleeding in atrial fibrillation. Am J Cardiol 2014; 113: 662-668 